\title{
Do cash transfer programmes yield better health in the first year of life? A systematic review linking low- income/middle-income and high-income contexts
}

\author{
Arjumand Siddiqi, ${ }^{1,2,3}$ Akshay Rajaram, ${ }^{4}$ Steven P Miller ${ }^{2}$
}

\begin{abstract}
'Dalla Lana School of Public Health, University of Toronto, Toronto, Ontario, Canada ${ }^{2}$ Department of Paediatrics, The Hospital for Sick Children and the University of Toronto, Toronto, Ontario, Canada ${ }^{3}$ Gillings School of Global Public Health, University of North Carolina, Chapel Hill, North Carolina, USA

${ }^{4}$ Faculty of Medicine, Queen's University, Kingston, Ontario, Canada
\end{abstract}

\section{Correspondence to} Dr Arjumand Siddiqi, Dalla Lana School of Public Health, University of Toronto, Toronto, ON M5T 3M7, Canada; aa.siddiqi@utoronto.ca

Received 15 October 2017 Revised 26 March 2018 Accepted 3 April 2018 Published Online First 28 April 2018

\section{Check for updates}

To cite: Siddiqi A, Rajaram A Miller SP. Arch Dis Child 2018:103:920-926.

\begin{abstract}
Introduction Decades of research unequivocally demonstrates that no matter the society, socioeconomic resources are perhaps the most fundamental determinants of health throughout the life course, including during its very earliest stages. As a result, societies have implemented 'cash transfer' programmes, whichprovide income supplementation to reduce socioeconomic disadvantage among the poorest families with young children. Despite this being a common approach of societies around the world, research on effects of these programmes in low-income/middleincome countries, and those in high-income countries has been conducted as if they are entirely distinct phenomena. In this paper, we systematically review the international literature on the association between cash transfer programmes and health outcomes during the first year of life.
\end{abstract}

Methods We conducted a systematic review based on Preferred Reporting Items for Systematic Reviews and Meta-Analyses protocol. Using a variety of relevant keywords, we searched MEDLINE, EMBASE, CINAHL, Cochrane Reviews, EconLit and Social Sciences Citations Index.

Results Our review yielded 14 relevant studies. These studies suggested cash transfer programmes that were not attached to conditions tended to yield positive effects on outcomes such as birth weight and infant mortality. Programmes that were conditional on use of health services also carried positive effects, while those that carried labour-force participation conditionalities tended to yield no positive effects.

Discussion Given several dynamics involved in determining whether children are healthy or not, which are common worldwide, viewing the literature from a global perspective produces novel insights regarding the tendency of policies and programmes to reduce or, to exacerbate, the effects of socioeconomic disadvantage on child health.

\section{INTRODUCTION}

Decades of research tragically demonstrates that the negative consequences of being poor are immediately apparent, influencing outcomes even during the first year of life. ${ }^{1}$ This is because having fewer socioeconomic resources exposes children (directly, or in utero through mothers' exposures) to a range of negative circumstances that underlie nearly every aspect of infant health and development. ${ }^{2}$ Moreover, outcomes during the first year of life are associated with poorer health outcomes throughout

\section{What is already known on this topic?}

A strong body of research confirms the role of socioeconomic resources in the production of infant health.

- Around the world, cash transfer interventions have been used to bolster the socioeconomic resources of poor families.

- Studies have assessed the impacts of these interventions on infant health.

\section{What this study adds?}

This study reviews and unifies research on the impact of cash transfer interventions on the health of infants in low-income/middle-income and high-income countries.

- Results point to key considerations for intervention planning.

- They also suggest a need to understand not only absolute gains in health resulting from cash transfer interventions, but also gains in health relative to others in society.

the life course, from developmental setbacks in childhood through to cardiovascular disease and premature mortality in late adulthood. ${ }^{3}$ The science is rather unequivocal ${ }^{4}$ : nurturing the early lives of children is critical, and making sure that every family is endowed with sufficient fundamental socioeconomic resources is the most effective means of ensuring a variety of nurturing conditions. ${ }^{35}$

The international development community has been very motivated to respond to this evidence. Several low-income/middle-income countries around the world have been implementing 'cash transfer' programmes, which provide income supplements to the poorest families with young children. Cash transfer programmes are generally divided into two types. The first are conditional cash transfer programmes, in which receipt of cash supplements is dependent on family engagement in accessing healthcare services and, for older children, education. Services are largely provided free of charge, ostensibly with the intention of boosting the effects of income on health and on human capital development. The second are 'unconditional cash transfer' programmes, in which receipt of cash supplements is free of any such obligations. ${ }^{6}$ 
High-income countries, driven by similar evidence and motivations, have also been engaging in interventions to reduce the burden of poverty for families with young children. ${ }^{78}$ These interventions are effectively also cash transfer programmes, although they have not been named as such, instead usually being termed 'welfare' programmes, 'social assistance' programmes or something similar. ${ }^{7910}$ These programmes even have a similar bifurcated typology. In the first set are conditional income supplementation programmes, which primarily require parents to hold employment in order to maintain programme eligibility. ${ }^{11}$ These are pervasive in the USA, Canada and the UK. ${ }^{7}$ The second set are unconditional income supplementation programmes, which the Nordic countries have come to typify. ${ }^{7}$

Thus, cash transfer programmes in low-income/middle-income and high-income countries have a lot of prima facie similarities. They also have a deeper set of common motivations. First, although the absolute levels of poverty are obviously much worse in low-income/middle-income countries than in high-income countries, the literature has demonstrated that it is absolute poverty, and relative poverty within one's society that determines health outcomes. ${ }^{5}{ }^{12}$ After all, this is why we see income differentials in health status even in high-income countries. ${ }^{5}$

Second, both low-income/middle-income and high-income countries have been moved to act by a similar set of economic and sociopolitical reasons. There are clear financial costs of poor health, namely through health expenditures that all countries and lending agencies seek to avoid. ${ }^{13}$ There are also more indirect financial effects of having a health-compromised citizenry, notably the ability of nations to build their human capital, which in turn influences productivity and other factors that underlie economic growth. ${ }^{13} 14$

Finally, in the last several decades, ideology, in the form of 'neoliberalism', has also been an important driver of global antipoverty policies. ${ }^{15}$ In its pithiest description, neoliberalism is a philosophical and policy orientation that places responsibility for one's economic security (and that of one's family) in the hands of individuals, rather than in the hands of governments. Neoliberal orientations to poverty and poverty reductionincluding the design of cash transfer programmes-largely stem from influential figures and institutions in the USA, and have been exported throughout the world via international agencies such as the World Bank and International Monetary Fund. ${ }^{15} 16$

For these reasons, we suggest that there are merits in creating more connections between the low-income/middle-income and high-income literatures on cash transfer programmes. In this study, we conduct a systematic review of the current body of research from around the world on the effects of cash transfer programmes on health outcomes during the first year of life, an age period that is significant for future health, and during which we have comparable outcomes across countries.

\section{METHODS}

\section{Literature search and search strategy}

Table 1 describes an overview of the search strategy we employed in PICO (Population/Problem, Intervention/Exposure, Comparison, Outcome) format, which was developed in conjunction with a health sciences librarian. The main exposure of interest was any policy or programme that was intended to address socioeconomic disadvantage by providing a direct income/cash transfer. Search terms thus included: cash transfer programme, conditional cash transfer programme, unconditional cash transfer programme, policy, social policy, economic policy, public policy, programme, benefits, social welfare and
Table 1 Search terms for systematic review on the effects of cash transfer programmes on child health

\begin{tabular}{|c|c|}
\hline $\begin{array}{l}\text { Component of review } \\
\text { topic }\end{array}$ & Search terms \\
\hline Population & Child, neonatal, infant \\
\hline $\begin{array}{l}\text { Intervention: policy or } \\
\text { programme }\end{array}$ & $\begin{array}{l}\text { Policy, social policy, economic policy, public policy, } \\
\text { programme, benefit*, social welfare or TANF, EITC, } \\
\text { Aid to Families with Dependent Children, PRWA, } \\
\text { FLMA, tax, cash transfer*, conditional cash transfer*, } \\
\text { unconditional cash transfer*, income supplement* }\end{array}$ \\
\hline Health outcome & Birth weight, mortality \\
\hline $\begin{array}{l}\text { Statistical methods } \\
\text { (quasi-experimental } \\
\text { techniques) }\end{array}$ & $\begin{array}{l}\text { Difference-in-differences, propensity score, synthetic } \\
\text { control, regression discontinuity, instrumental variable, } \\
\text { and near-far matching, quasi experiment, natural } \\
\text { experiment }\end{array}$ \\
\hline
\end{tabular}

We restricted our search results to English, humans and paediatric age groups, abstracts, journal articles, systematic reviews, meta-analyses, reviews and observational studies. For CINAHL, we restricted search results to academic journals. Search terms within each row were combined with 'OR' and search terms across different rows were combined with 'AND'.

Wherever possible, we used medical subject headings (MeSH) in our search of the individual databases. In cases where MeSH headings were not available, we entered search terms as keywords.

For Medline and EMBASE, 'public policy' also included health policy or healthcare reform or nutrition policy. For CINAHL, we used 'public policy' or 'health policy'. For Cochrane Reviews, we exploded the term 'economic policy' within 'public policy'.

tax. To maintain a broad search, we did not specify particular child health outcomes. We searched 'health' and then restricted our results to papers describing health outcomes for children in the first year of life. In keeping with the primary objective of generating insights about the patterns and effects of cash transfer programmes that have been tested empirically, we restricted our search to peer-reviewed papers in well-recognised scientific databases, and to papers that used the most robust available methods for assessing policy effects (both in terms of study design and/ or statistical analysis), specifically experimental or 'quasi-experimental' techniques. These are listed in table 1.

We searched the following electronic databases from their inception until 27 June 2017: MEDLINE, EMBASE, CINAHL, Cochrane Reviews, EconLit and Social Sciences Citations Index. We restricted our search results to English, humans and paediatric age groups, abstracts, journal articles, systematic reviews, meta-analyses, reviews and observational studies. For CINAHL, we restricted search results to academic journals. Citations were imported into EndNote (Thomson Reuters 2016) and all duplicates were deleted.

\section{Eligibility}

Titles and abstracts were checked for relevance, separately by AS and AR. Studies were included if they empirically tested the influence of policies and/or programmes whose aim was to mitigate socioeconomic disadvantage through the provision of cash transfers for children aged $0-1$ year. Studies were excluded if they discussed programme and policy interventions to address socioeconomic disadvantage, but did not empirically test the intervention or if the population under investigation did not provide outcomes for children aged $0-1$ year.

\section{Data abstraction}

Two reviewers (AS and AR) independently abstracted all data using a standardised data abstraction form. We extracted key study descriptors, including authors, year of publication, 


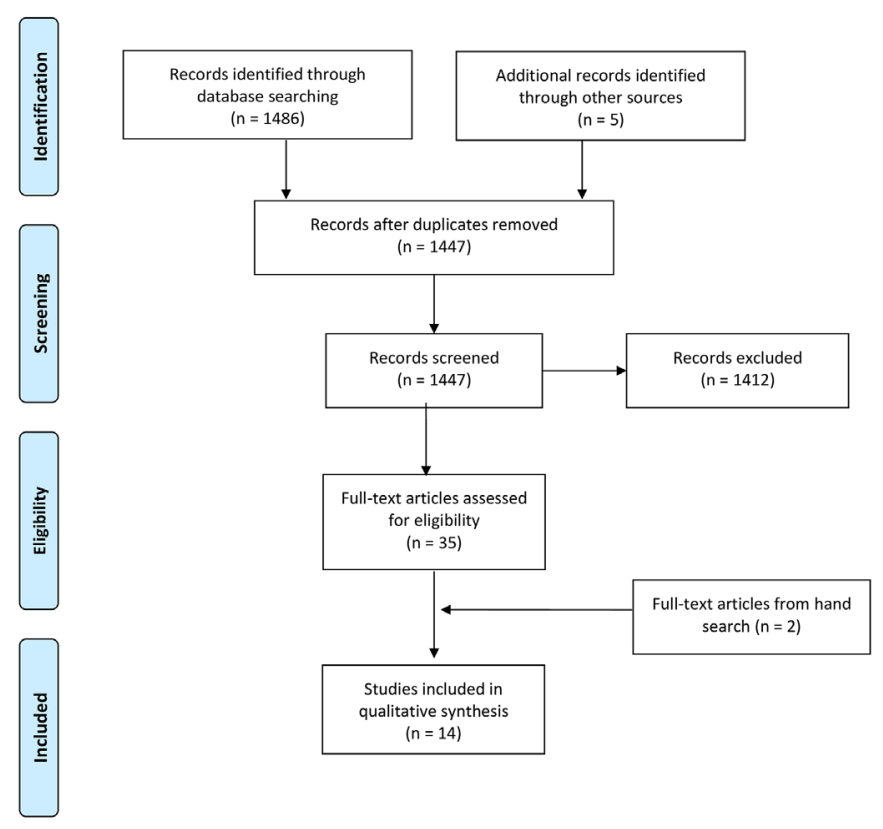

Figure 1 Search strategy based on Preferred Reporting Items for Systematic Reviews and Meta-Analyses guidelines. Adapted from Moher et al. ${ }^{37}$

article title, country and main research questions. We also extracted methodological features, including policy exposures, policy-exposed population, outcomes, data sources, analytic methods and principal findings.

\section{Assessment of study quality}

Studies were subject to quality assessment using questions drawn from a modified version of the Newcastle-Ottawa Scale, a widely used tool appraising the quality of observational studies, but still not sufficiently suited to addressing the quality of quasi-experimental studies without modification. ${ }^{17}$ The following more direct criteria were thus used to assess the methodological quality of the studies in our sample. Does the study draw on a representative and randomised sample of observations? Does the study use a direct measure of policy/ programme exposure? Does the study describe the characteristics of both exposed and unexposed groups? Does the study control for observed confounders? Does the study control for unobserved confounders? Does the study test the robustness of reported statistical estimates? Studies received one point for each item in the scale. Scores of 1-2 were defined as low quality. Scores of 3-4 were defined as medium quality. Scores of 5-6 were defined as high quality.

\section{Summary measures and synthesis}

Given the anticipated heterogeneity in outcomes, we did not aggregate abstracted data or conduct a meta-analysis. Instead, we summarised the principal findings of each study and qualitatively synthesised the results.

\section{RESULTS}

\section{Literature search}

Figure 1 summarises the total number of studies yielded by our search, and the process through which studies were excluded. Fourteen studies met criteria for inclusion into the final qualitative synthesis. Table 2 provides an overview of the studies and table 3 summarises study characteristics.
Population and sample characteristics

Eight studies were based in the USA, ${ }^{18-23}$ two in Canada, ${ }^{24} 25$ two in Mexico ${ }^{26} 27$ and one each in Brazil ${ }^{28}$ and Nepal. ${ }^{29}$ Eight studies relied on administrative linked data. ${ }^{18} 192123-2628$ Three studies used secondary survey data. ${ }^{20} 2229$ One study was based on a survey conducted in a subsample from a randomised trial of a cash transfer programme in Mexico. ${ }^{27}$

\section{Outcomes}

Birth weight was the most common outcome examined $(n=10$ studies). ${ }^{19-25} 27$ Mortality (neonatal and postneonatal) was also a frequently measured outcome ( $n=5$ studies). ${ }^{18} 25262829$ Two studies also explored gestational age, and two studied Apgar scores. $^{24}$

\section{Programme/policy exposures}

Programmes and policies fit into one of three categories: (a) those that were universal (ie, provided to the whole population, and not just a low-income subpopulation) and unconditional (requiring nothing of recipients) $(n=3),{ }^{25} 29$ (b) those that were targeted to a low-income population and were unconditional $(n=3)^{22-24}$ and (c) those that were targeted to a low-income population and were accompanied by conditions expected of recipients in exchange for benefits $(n=8) .{ }^{18-2126-28}$

One universal programme occurred in the context of a randomised trial conducted with families in rural Manitoba, Canada during the mid-1970s ${ }^{25}$. Families randomised to the cash transfer intervention were provided with income supplementation on a sliding scale. Another universal programme was unfolded in Alaska, where residents were provided with equal dividends derived from a state-fund that was established from oil-drilling-rights revenues. A third occurred in the context of a Nepalese policy, whereby those aged over 75 years were given a flat rate supplement. ${ }^{29}$

The three unconditional targeted cash transfer programmes were located in North America. ${ }^{2-24}$ Only one, is ongoing; a contemporary policy from Manitoba, Canada that provides a prenatal cash benefit to pregnant mothers on social assistance. ${ }^{24}$ Another was an experimental income supplementation programme that occurred in Gary, Indiana during the early 1970s, in which low-income residents of the town were randomised to receive a negative income tax intervention. ${ }^{23}$

Finally, Aid to Families with Dependent Children (AFDC), a programme that was eliminated during the mid-1990s, which provided income supplementation to low-income families, was also examined. While one study evaluated the programme, another examined 1990s transformation of social assistance in the USA (often called 'welfare reform'), through which AFDC was eliminated and replaced with what amounted to a targeted, conditional cash transfer programme. ${ }^{18} 22$

Eight studies examined targeted, conditional cash transfer programmes. Two programmes (Mexico: Oportunidades/ Progresa, Brazil: Bolsa Família) came with conditions regarding use of healthcare and school attendance for school-aged children. $^{26-28}$ Four US studies examined another targeted, conditional cash transfer programme, the Earned Income Tax Credit (EITC), ${ }^{19-21}$ also part of 'welfare reform', which provides a refundable tax credit to employed low-earning to moderate-earning Americans.

\section{Methods}

All of the studies were based on data derived either from (a) experimental designs, in which families had explicitly been 
Table 2 Overview of studies in systematic review $(n=14)$

\begin{tabular}{ccl}
\hline Author (date) & Country & Programme details \\
\hline Universal unconditional programmes ( $\mathrm{n}=3$ ) $^{25}$ & Canada & $\begin{array}{l}\text { MINCOME: a mid-1970s experimental guaranteed annual } \\
\text { income programme with transfer amounts based on a }\end{array}$ \\
& sliding scale (depending on income from other sources). \\
& Recipients: All residents of Dauphin, Manitoba.
\end{tabular}

\begin{tabular}{|c|c|c|}
\hline $\begin{array}{l}\text { Li and } \\
\text { Mora }^{29}\end{array}$ & Nepal & $\begin{array}{l}\text { Old Age Allowance Programme (OAAP): a universal flat } \\
\text { rate pension } \\
\text { Recipients: Residents aged } 75 \text { years or older. }\end{array}$ \\
\hline $\begin{array}{l}\text { Chung } \\
\text { et } a l^{38}\end{array}$ & USA & $\begin{array}{l}\text { Alaska Permanent Fund Dividend (APFD): an annual } \\
\text { dividend derived from a state fund, which accumulates } \\
\text { through the sale of oil drilling rights. On average, families } \\
\text { with newborns received US\$1961. } \\
\text { Recipients: With the exception of having being a resident } \\
\text { of Alaska for at least } 6 \text { months, an equal dividend is giver } \\
\text { unconditionally to every resident of the state. }\end{array}$ \\
\hline \multicolumn{3}{|c|}{ Targeted unconditional programmes $(\mathrm{n}=3)$} \\
\hline $\begin{array}{l}\text { Brownell } \\
\text { et } a l^{24}\end{array}$ & Canada & $\begin{array}{l}\text { Healthy Baby Prental Benefit (HBPB): an income support } \\
\text { of up to US\$81.41 per month. } \\
\text { Recipients: Women in Manitoba, Canada during second } \\
\text { and third trimesters, with a documented income below } \\
\text { US\$32000 per year. }\end{array}$ \\
\hline
\end{tabular}

Evaluation details

Findings

Design and sample size:

Families were randomly selected to participate from

No significant differences in perinatal death and birth

Dauphin and were matched to controls from similarly small

rural communities.

Data source: Manitoba Population Health Research Data

Repository.

\section{Design and sample size:}

Treated group: OAAP eligible person in same household as infant $(n=211)$. Controls: those not living in household with OAAP eligible person $(n=13345)$.

Data source: Nepal Demographic and Health Survey from

1996 to 2001.

Design and sample size:

Difference-in-differences modelling to determine the

impact of APFD on birth outcomes in Alaska compared

with control states with no such fund ( $n=7.7$ million)

Data source: Vit

1978 to 1984)

Design and sample size:

2010 on welfare during pregnancy (total $n=15033$ : those receiving $\mathrm{HBPB}(n=10738)$ and those not receiving HBPB $(\mathrm{n}=3853)$.

Data source: Administrative linked data.
All infants born to Manitoba women from 2003 through

Receiving HPBP associated with: $29 \%$ reduction in risk of low birth weight ( $95 \% \mathrm{Cl} 0.63$ to 0.81$), 24 \%$ reduction in risk of preterm birth $(95 \% \mathrm{Cl} 0.69$ to 0.84$)$, $10 \%$ reduction in risk of small for gestation age $(95 \% \mathrm{Cl}$ 0.81 to 099 ) and $13 \%$ increase in large for gestational age $(95 \% \mathrm{Cl} 1.05$ to 1.23$)$

Population Attributable Fractions suggested HBPD associated with $21 \%$ reduction in low birth weight and $17.5 \%$ reduction in preterm birth in the population.

No significant association between AFDC and birth weight. Marginal association with increased birth $n=$ approximately 5000 children born between 1979 and 1988 with complete AFDC and birth weight data. Data source: National Longitudinal Survey of Youth (NLSY)

Design and sample size:

Treatment families were those eligible to receive various levels of income maintenance $(n=256)$. Control families were from Gary, Indiana, but not eligible for income maintenance $(n=148)$

Data source: Birth records of Gary Income Experiment participants and monthly income reports.

Targeted conditional programmes $(n=8)$

Barber and Mexico Oportunidades (formerly Progresa): a conditional cash Gertler $^{27}$ transfer programme based on age, including prenatal ca healthcare use and school attendance.

Recipients: Approximately 5 million low-income families urban and rural settings.

$\begin{array}{lll}\text { Barham }^{26} \quad \text { Mexico } & \begin{array}{l}\text { Oportunidades (formerly Progresa): a conditional cash } \\ \text { transfer programme based on age, including pre-natal } \\ \text { care, healthcare use and school attendance. } \\ \text { Recipients: Approximately } 5 \text { million low-income families } \\ \text { urban and rural settings. }\end{array} \\ \text { Shei }^{28} & \text { Brazil } & \begin{array}{l}\text { Bolsa Familia: monthly cash transfers attached to health } \\ \text { (routine growth monitoring, vaccinations, regular prenata } \\ \text { care) and educational (enrolment in school, minimum } \\ \text { attendance requirements) conditionalities. } \\ \text { Recipients: Poor households with per capita incomes } \\ \text { below a program-specific poverty line. }\end{array}\end{array}$

Bruckner USA Earned Income Tax Credit (EITC): tax refund disbursed et $a^{21} \quad$ to low-income families contingent on employment, with larger benefits to families with children. Credits increase with increasing income until a maximum threshold credit is reached (US\$4716). Median refund was US\$1130 during the study period.

Recipients: $95 \%$ of recipients of EITC were single or married couples with a qualifying child under the age of 19 years.

$\mathrm{Cho}^{18} \quad$ USA Personal Responsibility Work Opportunity and Reconciliation Act: ended the federal guarantee of income support, imposed lifetime limits on public assistance, created additional work requirements and allowed states to tie assistance to specified maternal behaviours. Recipients: Legislation largely affected poor families with children, especially immigrant families.
Design and sample size:

Two-staged random, probability-based sample of communities and households within communities. Total

$\mathrm{n}=840$ women $(\mathrm{n}=666$ beneficiary births, $\mathrm{n}=174 \mathrm{non}$ beneficiary births).

Data source: Fertility surveys and household interviews

Design and sample size:

Randomisation of 506 programme localities in seven states into treatment and control groups.

Data source: Mexican vital statistics data from 1992 to 2001.

Design and sample size:

Pooled, time series, cross-sectional design; sample sizes not provided.

Data source: Brazilian Unified Health System Database, Ministry of Social Development and Brazilian Institute of Geography and Statistics, at the municipal level, from 1998 to 2008 .

Design and sample size:

Used variables from the California Birth File to specify (1) gravid women who might have been eligible for an EITC benefit and (2) their children born during the study period $(n=70895)$

Data source: California Birth File from 1989 to 1997 (period of high EITC expansion and data consistency)

Design and sample size

Total $n=881854$ ( $n=562937$ foreign-born Mexican women and $n=318917$ comparison group native-born Mexican women).

Data source: National Centre for Health Statistics infant birth and death records on low-income Mexican women 2002 (after welfare reforms). from 1995 to 1996 (before welfare reforms) and 1999-

Beneficiary status associated with $127.3 \mathrm{~g}$ higher birth weight $(95 \% \mathrm{Cl} 21.3$ to 233.1$)$ and $4.6 \%$ decrease in ow birth weight.

Oportunidades was associated with a reduction in 3 deaths per 1000 live births, or $17 \%$ decline $(P=0.01)$. No significant association effect of Progresa on neonatal mortality rate.

While IMR was already falling prior to 2003, rate of decline increased after programme implementation. Average treatment effect was $9.3 \%$ decline in IMR and $24.3 \%$ decline in postneonatal IMR $(P<0.01)$, but no significant change in neonatal IMR.

Odds of very low birth weight increased 2 months immediately following EITC disbursement (OR 1.31 $95 \% \mathrm{Cl} 1.09$ to 1.58 ). Effect of EITC lagged at 3 or 4 months was also non-significant.

Children in the treatment group experienced 117.6$530.4 \mathrm{~g}$ higher birth weight than children in the control group.

\$ $\$ 1000$ of APFD was associated with a $17.7 \mathrm{~g}$ incre $0.7 \%$ in low birth weight. Apgar scores also showed $0.7 \%$ in low birth weight. Apgar scores also showed
improvement. Effects were largest for those with a high OAAP resulted in 7\%-8\% higher probability of surviv 12 months after birth (from a baseline probability of 12 months after birth (from a baseline probability of

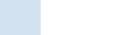




\begin{tabular}{|c|c|c|c|c|}
\hline Author (date) & Country & Programme details & Evaluation details & Findings \\
\hline $\begin{array}{l}\text { Hamad and } \\
\text { Rehkopf }^{20}\end{array}$ & USA & $\begin{array}{l}\text { EITC: tax refund disbursed to low-income families } \\
\text { contingent on employment, with larger benefits to } \\
\text { families with children. Credits increase with increasing } \\
\text { income until a maximum threshold credit is reached } \\
\text { (US\$4716). } \\
\text { Recipients: } 95 \% \text { of recipients of EITC were single or } \\
\text { married couples with a qualifying child under the age of } \\
19 \text { years. }\end{array}$ & $\begin{array}{l}\text { Design and sample size: } \\
\text { Multivariable regression and intstrumental variable } \\
\text { analysis of study sample women }(n=2985) \text { and their } \\
\text { children born during } 1986-2000 \text { years during which ETIC } \\
\text { payment size varied the most ( } n=4683 \text { ). } \\
\text { Data source: NLSY. }\end{array}$ & $\begin{array}{l}\text { Each additional US } \$ 1000 \text { of EITC payment was not } \\
\text { significantly associated with an increase in birth weight } \\
\text { of } 65.1 \mathrm{~g}(95 \% \mathrm{Cl}-0.46,130.6) \text {. } \\
\text { Results of instrumental variable analysis suggest no } \\
\text { significant effect of EITC in the overall sample, but } \\
\text { an increase in birth weight for women receiving the } \\
\text { payment in the second trimester. }\end{array}$ \\
\hline Strully et a $\left.\right|^{19}$ & USA & $\begin{array}{l}\text { EITC: tax refund disbursed to low-income families } \\
\text { contingent on employment, with larger benefits to } \\
\text { families with children. Credits increase with increasing } \\
\text { income until a maximum threshold credit is reached } \\
\text { (US\$ } \$ 716) \text {. } \\
\text { Recipients: } 95 \% \text { of recipients of EITC were single or } \\
\text { married couples with a qualifying child under the age of } \\
19 \text { years. }\end{array}$ & $\begin{array}{l}\text { Design and sample size: } \\
\text { Differences-in-differences modelling with sample limited to } \\
\text { unmarried mothers with a high school degree or less as a } \\
\text { way to capture those most likely to receive EITC. } \\
\text { Data source: Vital Statistics (the US Natality Detail File from } \\
1980 \text { to 2002). }\end{array}$ & $\begin{array}{l}\text { EITC was associated with an average increase in birth } \\
\text { weight of } 15.70 \mathrm{~g} \text { (SE: } 1.211 \text { ) among unmarried women } \\
\text { with high school education or less. }\end{array}$ \\
\hline $\begin{array}{l}\text { Hoynes et } \\
a l^{39} \\
(2015)\end{array}$ & USA & $\begin{array}{l}\text { EITC: tax refund disbursed to low-income families } \\
\text { contingent on employment, with larger benefits to } \\
\text { families with children. Credits increase with increasing } \\
\text { income until a maximum threshold credit is reached } \\
\text { (US\$4716). } \\
\text { Recipients: } 95 \% \text { of recipients of EITC were single or } \\
\text { married couples with a qualifying child under the age of } \\
19 \text { years. }\end{array}$ & $\begin{array}{l}\text { Design and sample size: } \\
\text { Differences-in-differences modelling of three EITC time } \\
\text { ranges for single mothers aged } 18 \text { years or older with less } \\
\text { than a high school education singleton births ( } n=35467- \\
47687 \text { ) } \\
\text { Data source: Vital statistics (the US Natality Detail File from } \\
1984 \text { to } 1998 \text { and Current Population Survey. }\end{array}$ & $\begin{array}{l}\text { US } \$ 1000 \text { of EITC was associated with a } 2 \%-3 \% \text { decline } \\
\text { in low birth weight and an increase of } 6.4 \mathrm{~g} \text { in mean } \\
\text { birth weight. Preterm birth, small for gestational age } \\
\text { and Apgar score also improved. Effects were largest for } \\
\text { black infants and smallest for white infants. }\end{array}$ \\
\hline
\end{tabular}

Table 3 Overview of study characteristics

\begin{tabular}{|l|l|}
\hline Characteristics & $\begin{array}{l}\text { Number of } \\
\text { studies }\end{array}$ \\
\hline Country & \\
\hline USA & 8 \\
\hline Canada & 2 \\
\hline Mexico & 2 \\
\hline Brazil & 1 \\
\hline Nepal & 1 \\
\hline Data source & \\
\hline Survey data & 4 \\
\hline Population-based administrative data & 10 \\
\hline Outcomes & \\
\hline Birth weight & 9 \\
\hline Infant mortality & 3 \\
\hline Perinatal mortality & 1 \\
\hline Probability of survival & 1 \\
\hline Gestational age & 2 \\
\hline Apgar score & 2 \\
\hline Policy exposures & \\
\hline Universal unconditional programmes & 3 \\
\hline Targeted unconditional programmes & 3 \\
\hline Targeted conditional programmes & 8 \\
\hline Analysis methods & 2 \\
\hline Regression with instrumental variable analysis & 2 \\
\hline Time series regression & 5 \\
\hline Difference-in-differences & 2 \\
\hline Fixed effects modelling & \\
\hline Propensity score matching & \\
\hline & \\
\hline
\end{tabular}

randomised in a cash transfer intervention, ${ }^{2325-28}$ or (b) quasi/ natural-experimental designs, in which a programme or policy intervention had been implemented in a way that allowed investigators the opportunity to mimic an experimental design. $^{18-22242930}$

The statistical strategies used to analyse the data varied. Studies that drew on experimental designs used fixed effects regression modelling or instrumental variable analysis in order to further control for unmeasured sources of confounding. ${ }^{2325-28}$ Among quasi-experimental studies, difference-in-differences was the most common analytic approach. ${ }^{18} 1929$ Studies also used propensity score matching, ${ }^{24}$ instrumental variable analysis ${ }^{20}$ and more basic forms of regression. ${ }^{21} 22$

\section{Quality of studies}

All studies were judged to be of high quality. They all drew on representative or randomised samples. They all measured a direct policy or programme exposure. They all controlled for observed confounders, and attempted to control for unknown confounders. They all described their control groups, and they all tested the robustness of their reported statistical estimates.

\section{Findings}

We considered the findings across types of cash transfer programmes, and where possible, within these strata, across country income levels.

Universal and unconditional cash transfer programmes. Two studies demonstrated positive effects. In Alaska, a US\$1000 unconditional dividend was associated with a $17.7 \mathrm{~g}$ increase in birth weight, and a decrease in between $0.4 \%$ and $0.7 \%$ in low birth weight. In Nepal, children living in households with grandparents eligible for old-age allowance had a 7\%-8\% higher probability of survival after 12 months of birth. ${ }^{29}$ The Canadian study of a guaranteed income experiment suggested no significant differences in birth outcomes, although empirical estimates were not provided. ${ }^{25}$

Targeted and unconditional cash transfer programmes. All three low-income-targeted unconditional programmes demonstrated mainly improved outcomes during the first year of life. The Gary Experiment yielded 117.6-530.4 g higher birth weight than children in the control group, depending on risk characteristics of mothers. ${ }^{23}$ The other US-based study found that AFDC was marginally associated with increased birth weight among poor whites (beta $=32.00, \mathrm{SE}: 16.11$ ), but no significant change for other groups. ${ }^{22}$ The study from Manitoba, Canada suggested a monthly supplement was associated with a several positive outcomes, including a $29 \%$ reduction in the risk of low birth weight (95\% CI 0.63 to 0.81$)$, a $24 \%$ reduction in risk of 
preterm birth (95\% CI 0.69 to 0.84$)$, a $10 \%$ reduction in risk of small for gestation age (95\% CI 0.81 to 099 ) and a $13 \%$ increase in large for gestational age (95\% CI 1.05 to 1.23$){ }^{24}$

Targeted and conditional cash transfer programmes. Results from targeted, conditional cash transfer programmes suggested that, in the USA, those that were accompanied by work conditions generally did not yield positive effects. Reforms to the US welfare system were associated with an increase in infant mortality rate for children of foreign-born Mexican women of 3.1 deaths per 1000 live births (SE: 0.001), from a baseline rate of 4.23-6.22 deaths per 1000 live births depending on the state. ${ }^{18}$ In a more socioeconomically restricted sample, welfare reform was associated with an increase of 5.9 deaths per 1000 live births (SE: 0.002). Studies on EITC were divided. Two studies found positive effects. In one, US $\$ 1000$ of EITC was associated with a $2 \%-3 \%$ decline in low birth weight and an increase of $6.4 \mathrm{~g}$ in mean birth weight. Preterm birth, small for gestational age and Apgar score were also improved. In another study, EITC was associated with an average increase in birth weight of $15.70 \mathrm{~g}$ (SE: 1.211) among unmarried women with high school education or less. Two other studies found no significant effects of EITC. ${ }^{19-21}$

By contrast, health service use conditionalities in emerging economies were associated with improved outcomes. The Mexican programme, Opportunidades/Progresa, yielded $127.3 \mathrm{~g}$ higher birth weight (95\% CI 21.3 to 233.1 ) and therefore a $4.6 \%$ decrease in low birth weight, and a reduction in 3 deaths per 1000 live births, or $17 \%$ decline $\mathrm{P}=0.01 .^{2627}$ And, in the context of already falling infant mortality rate (IMR), the Brazilian programme, Bolsa Família was associated with a faster rate of decline: a $9.3 \%$ decline in infant mortality rate, and a $24.3 \%$ decline in postneonatal infant mortality rate (death between 28 days and 1 year of age) $(\mathrm{P}<0.01)$, but no significant change in neonatal IMR (death between birth and 28 days of age). ${ }^{28}$

\section{DISCUSSION}

Despite many commonalities, research on the effects of cash transfer programmes in low-income/middle-income countries, and those in high-income countries has been treated as if poverty, its effects on health, and the role of cash transfer programmes are entirely distinct phenomenon in these two groups of countries. In order to begin to unify these literatures, we conducted a systematic review of studies that have examined the effects of cash transfer programmes on the outcomes of children during the first year of life.

While our review uncovered only 14 papers, which together yielded some mixed results, 3 patterns stood out. First, in both low-income/middle-income and high-income countries, cash transfer programmes that do not carry conditions seem mostly to be beneficial. ${ }^{22-2429}$ Second, in middle-income countries, cash transfer programmes that are conditional on use of health and educational services also yield health benefits. ${ }^{262731}$ Finally, in the context of high-income countries, programmes that carry work requirements are not associated with improved health of young children. ${ }^{18-21}$

Within low-income/middle-income and high-income country literatures, these results are largely consistent with existing studies of other health outcomes in other age groups. ${ }^{30} 3233$ Prior literature indicates several possible explanations for our findings. Within the literature from low-income/middle-income countries, there is no clear empirical 'winner' between conditional and unconditional cash transfer programmes, with results appearing to depend on outcomes. ${ }^{34}$ In high-income countries, work conditionalities have rather uniformly been found to be detrimental to health status, because unstable jobs with poor working conditions may actually be worse for health than having no job at all. ${ }^{3536}$

On the other hand, our study is limited in its capacity to deliver strong conclusions. With a small sample size, it is difficult to know how replicable, or generalisable, the findings are from the studies we reviewed. Moreover, without formal meta-analytic empirical estimates, it is difficult to be certain of the effects that we have qualitatively described.

The studies themselves were also limited in some key respects. For example, the existing literature on the association between socioeconomic resources and child health suggests that it is absolute levels of income, and income-level relative to others in society, that matters. This is why income differentials in health are observed even in high-income countries. However, studies do not report on the extent to which cash transfer programmes close the relative gap in health status across income levels within societies, instead reporting only the absolute change in health status among cash transfer recipients.

It is clear that much more research is warranted to understand how best to bolster the socioeconomic resources of children.

\section{CONCLUSION}

By jointly reviewing the literature in low-income/middle-income and high-income countries, we were able to infer some broad global trends in cash transfer programmes that are worthy of further inquiry. By and large, cash transfer programmes around the world are accompanied by conditionalities and, they primarily aim to reduce absolute poverty levels, although not relative poverty levels. We were also able to examine whether conditionalities themselves are harmful, or whether it is the substance and context of conditionalities that seems to matter, with our results suggesting the latter is the case.

Contributors AS conceptualised and wrote the study. AR conducted the literature search, under the guidance of AS. AR and SPM refined the conceptualisation of the study, developed the search strategy and provided feedback on drafts.

Funding AS is supported by the Canada Research Chair in Population Health Equity. SPM is supported by the Bloorview Children's Hospital Chair in Paediatric Neuroscience.

Competing interests None declared.

Provenance and peer review Not commissioned; externally peer reviewed.

(c) Article author(s) (or their employer(s) unless otherwise stated in the text of the article) 2018. All rights reserved. No commercial use is permitted unless otherwise expressly granted.

\section{REFERENCES}

1 Houweling TA, Kunst AE. Socio-economic inequalities in childhood mortality in lowand middle-income countries: a review of the international evidence. Br Med Bull 2010;93:7-26.

2 Siddiqi A, Jones MK, Erwin PC. Does higher income inequality adversely influence infant mortality rates? Reconciling descriptive patterns and recent research findings. Soc Sci Med 2015;131:82-8.

3 Marmot M, Friel $S$, Bell $R$, et al. Closing the gap in a generation: health equity through action on the social determinants of health. Lancet 2008;372:1661-9.

4 Campbell F, Conti G, Heckman JJ, et al. Early childhood investments substantially boost adult health. Science 2014;343:1478-85.

5 Hertzman C, Siddiqi A, Hertzman E, et al. Bucking the inequality gradient through early child development. BMJ 2010;340:c468.

6 de Janvry A, Sadoulet E. Making conditional cash transfer programs more efficient: designing for maximum effect of the conditionality. World Bank Econ Rev 2006;20:1-29.

7 Esping-Andersen G. The three worlds of welfare Capitalism. Princeton University Press: Princeton, NJ, 1990.

8 Esping-Andersen G. A child-centred social investment strategy. In: Why we need a new welfare state. Oxford, UK: Oxford University press, 2002:26-67. 
9 Beaujot R, Liu J. Children, social assistance and outcomes: Cross National Comparisons: Luxembourg Income Study Working Paper. No. 304. 2002.

10 Russell Sage F, Schoeni RF. Making Americans healthier: social and economic policy as health policy. New York: Russell Sage Foundation, 2008.

11 Meyers MK, Gornick JC, Peck LR. Packaging support for low-income families: policy variation across the United States. J Policy Anal Manage 2001;20:457-83.

12 Hertzman C, Boyce T. How experience gets under the skin to create gradients in developmental health. Annu Rev Public Health 2010;31:329-47.

13 Doyle 0 , Harmon CP, Heckman JJ, et al. Investing in early human development: timing and economic efficiency. Econ Hum Biol 2009;7:1-6.

14 Carneiro P, Heckman J. Human Capital Policy. 2003:821.

15 Evans P, Sewell JWH, et al. The neoliberal era: ideology, policy, and social effects. In: Hall P, Lamont M, eds. Social Resilience in the Neoliberal Era. New York: Cambridge University Press, 2013.

16 Fourcade-Gourinchas M, Babb SL. The rebirth of the liberal creed: paths to neoliberalism in four Countries. Am J Sociol 2002;108:533-79.

17 Herzog R, Álvarez-Pasquin MJ, Díaz C, et al. Are healthcare workers' intentions to vaccinate related to their knowledge, beliefs and attitudes? A systematic review. BMC Public Health 2013;13:154.

18 Cho RM. Effects of welfare reform policies on Mexican immigrants' infant mortality rates. Soc Sci Res 2011;40:641-53.

19 Strully KW, Rehkopf DH, Xuan Z. Effects of prenatal poverty on infant health: state earned income tax credits and birth weight. Am Sociol Rev 2010;75:534-62.

20 Hamad R, Rehkopf DH, Poverty RDH. Poverty, pregnancy, and birth outcomes: a study of the earned income tax credit. Paediatr Perinat Epidemiol 2015;29:444-52.

21 Bruckner TA, Rehkopf DH, Catalano RA. Income gains and very low-weight birth among low-income black mothers in California. Biodemography Soc Biol 2013;59:141-56.

22 Currie J, Cole N. Welfare and child health: the link between AFDC participation and birth weight. The American Economic Review 1993;83:971-85.

23 Kehrer BH, Wolin CM. Impact of income maintenance on low birth weight: evidence from the Gary Experiment. J Hum Resour 1979;14:434-62.

24 Brownell MD, Chartier MJ, Nickel NC, et al. Unconditional prenatal income supplement and birth outcomes. Pediatrics 2016;137:e20152992.

25 Forget EL. The town with no poverty: the health effects of a Canadian guaranteed annual income field experiment. Canadian Public Policy 2011;37:283-305.
26 Barham T. A healthier start: The effect of conditional cash transfers on neonatal and infant mortality in rural Mexico. J Dev Econ 2011;94:74-85.

27 Barber SL, Gertler PJ. The impact of Mexico's conditional cash transfer programme, Oportunidades, on birthweight. Trop Med Int Health 2008;13:1405-14.

28 Shei A. Brazil's conditional cash transfer program associated with declines in infant mortality rates. Health Aff 2013;32:1274-81.

29 Li Y, Mora R. Re-assessing the impact of the grandparent's income on the infant mortality rate: an evaluation of the old age allowance program in Nepal. World Dev 2016;87:333-48.

30 Basu S, Meghani A, Siddiqi A. Evaluating the health impact of large-scale public policy changes: classical and novel approaches. Annu Rev Public Health 2017;38:351-70.

31 Shei A, Costa F, Reis MG, et al. The impact of Brazil's Bolsa Família conditional cash transfer program on children's health care utilization and health outcomes. BMC Int Health Hum Rights 2014;14:10.

32 Ranganathan M, Lagarde M. Promoting healthy behaviours and improving health outcomes in low and middle income countries: a review of the impact of conditional cash transfer programmes. Prev Med 2012;55:S95-105.

33 Lagarde $\mathrm{M}$, Haines A, Palmer N. The impact of conditional cash transfers on health outcomes and use of health services in low and middle income countries. Cochrane Database Syst Rev 2009;67.

34 Lachman ME, Weaver SL. The sense of control as a moderator of social class differences in health and well-being. J Pers Soc Psychol 1998;74:763-73.

35 Basu S, Rehkopf DH, Siddiqi A, et al. Health behaviors, mental health, and health care utilization among single mothers after welfare reforms in the 1990s. Am J Epidemiol 2016:183:531-8

36 Shaefer HL, Ybarra M. The welfare reforms of the 1990s and the stratification of material well-being among low-income households with children. Child Youth Serv Rev 2012;34:1810-7

37 Moher D, Liberati A, Tetzlaff J, et al. Preferred reporting items for systematic reviews and meta-analyses: the PRISMA statement. PLoS Med 2009;6:e1000097.

38 Chung W, Ha H, Kim B. Money transfer and birth weight: evidence from the Alaska permanent fund dividend. Econ Inq 2016;54:576-90.

39 Hoynes H, Miller D, Simon D. Income, the earned income tax credit, and infant health. Am Econ J Econ Policy 2015;7:172-211. 